\title{
Immunocytochemical expression of growth factors by odontogenic jaw cysts
}

Tiejun Li, Roger M Browne, John B Matthews

\begin{abstract}
Aim-To determine the immunocytochemical pattern of expression of transforming growth factor (TGF) $\alpha$, epidermal growth factor (EGF), and TGF $\beta$ in the three most common types of odontogenic jaw cyst
\end{abstract}

Methods-Growth factor expression was detected in paraffin wax sections of odontogenic cysts ( 27 odontogenic keratocysts, 10 dentigerous cysts, and 10 radicular cysts) using a streptavidin-biotin peroxidase technique with monoclonal antibodies directed against TGF $\alpha$ (clone 213-4.4) and TGFB (clone TB21) and a polyclonal antibody directed against EGF (Z-12).

Results-The epithelial linings of all cysts showed reactivity for TGFa which was mainly localised to basal and suprabasal layers. Odontogenic keratocyst linings expressed higher levels of TGFa than those of dentigerous and radicular cysts, with $89 \%(24 / 27)$ of odontogenic keratocysts exhibiting a strong positive reaction compared with $50 \%$ (five of 10 ) of dentigerous and radicular cysts, respectively. EGF reactivity was similar in all cyst groups, weaker than that for TGF $\alpha$ and predominantly suprabasal. TGFa and EGF were also detected in endothelial cells, fibroblasts and inflammatory cells within the cyst walls. The most intense TGF $\beta$ staining in odontogenic cysts was extracellular within the fibrous tissue capsules, irrespective of cyst type.

Conclusions-These results, together with previous studies of EGF receptor, indicate differential expression of TGF $\alpha$, EGF and their common receptor between the different types of odontogenic cyst, suggesting that these growth factors (via autocrine or paracrine, or both, pathways) may be involved in their pathogenesis.

(F Clin Pathol: Mol Pathol 1997;50:21-27)

Keywords: EGF; TGF $\alpha$; odontogenic cysts; TGF $\beta$

Unit of Oral Pathology, School of Dentistry, University of Birmingham, St Chad's Queensway, Birmingham B4 6NN

Correspondence to: Dr J B Matthews.

Accepted for publication 28 October 1996
Transforming growth factor alpha (TGF $\alpha)$ and epidermal growth factor (EGF) are structurally related mitogens that regulate cell growth and differentiation. ${ }^{1}{ }^{2}$ Both polypeptides are ligands bound by the external domain of the $170 \mathrm{kD}$ epidermal growth factor receptor (EGF-R) localised to the cell surface membranes of many cell types. ${ }^{34}$ Ligand-receptor binding activates a tyrosine specific protein kinase which is part of the intracellular domain of the
EGF-R and leads to intracellular changes preparing the cell for DNA synthesis and cell division. ${ }^{2356}$

EGF was first isolated from mouse submandibular glands and found to accelerate incisor tooth eruption and eyelid opening in the developing animal. ${ }^{1}$ It is a potent mitogen which stimulates the growth and differentiation of a variety of mammalian cells, including epithelial cells. ${ }^{17}$ TGF $\alpha$ was originally isolated from retrovirally transformed 3T3 fibroblasts as a factor that stimulated anchorage independent growth. ${ }^{2}$ Like EGF, high level expression of TGF $\alpha$ is mitogenic in cell lines possessing EGF receptors. ${ }^{8}$ Both ligands have been identified in various human fetal and adult tissues $^{9-11}$ and high levels of TGF $\alpha$, and sometimes EGF, have been detected in a wide variety of neoplastic tissues including odontogenic tumours. ${ }^{1213}$

Recent studies have suggested that members of the EGF family (that is, EGF, TGF $\alpha$, and EGF-R) are involved in regulation and control of tooth development. ${ }^{14-18}$ Administration of EGF or TGF $\alpha$ to newborn mice accelerates incisor eruption. ${ }^{1920}$ Exogenous EGF has been shown to inhibit early mouse tooth morphogenesis and cytodifferentiation in vitro, and to decrease tooth size in vivo. ${ }^{1820-22}$ Furthermore, EGF antisense oligodeoxyribonucleotides can block murine odontogenesis in vitro. ${ }^{17}$ Although studies on EGF-R expression by the tooth germ are contradictory, ${ }^{14} 1822$ one recent study has demonstrated that EGF-R mRNA and immunoreactive cells are mostly located in the epithelial elements of human tooth germ and its expression is subjected to temporospatial variation at different stages of tooth development. ${ }^{13}$ As different types of odontogenic cyst arise from the epithelial remnants formed at different stages of tooth development, they may reflect the cellular and molecular events occurring during normal odontogenesis, particularly in developmental cyst types. In recent studies, we have demonstrated differential expression of EGF receptors and parathyroid hormone related protein (PTHrP) by, and qualitative and quantitative differences in proliferative state between, the different types of odontogenic cyst. ${ }^{23-26}$ The aim of this study was to determine the immunocytochemical expression of TGF $\alpha$ and $\mathrm{EGF}$ in different types of odontogenic cyst. As TGF $\beta$, a multifunctional growth factor, has also been implicated in tooth development, possibly as a signalling regulator of epithelial differentiation, ${ }^{27} 28$ its distribution in different cyst types was also studied. 

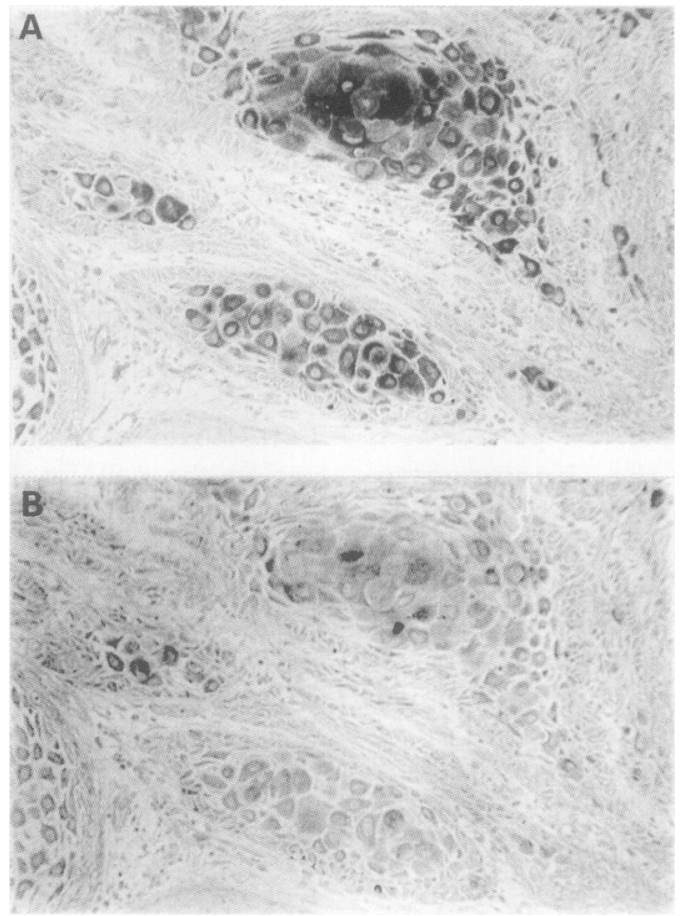

Figure 1 Staining of an oral squamous cell carcinoma with antibody directed against TGFa preincubated overnight with buffer $(A)$ and a 10-fold excess by weight of TGFa (B).

\section{Methods}

TISSUES

Forty seven odontogenic cysts (27 odontogenic keratocysts, 10 dentigerous cysts, and 10 radicular cysts) were retrieved from the files of the Unit of Oral Pathology. Of the 27 odontogenic keratocysts, 10 were primary, occurring as a solitary lesion in otherwise healthy patients; eight cysts were recurrent lesions within a period of three to 10 years after primary surgery; nine cysts were from six patients known to have naevoid basal cell carcinoma syndrome (NBCCS). All tissue specimens were fixed in $10 \%$ neutral buffered formalin (18-48 hours), processed routinely and embedded in paraffin wax. Only undecalcified specimens or specimens that had been decalcified in $10 \%$ formic acid for less than six hours were chosen to minimise possible inconsistencies in immunoreactivity as a result of such processing variables. Routinely fixed and processed specimens of human skin, salivary glands and oral squamous cell carcinomas were used as positive controls.

\section{IMMUNOCYTOCHEMISTRY}

Expression of TGF $\alpha$, EGF and TGF $\beta$ was detected using a streptavidin-biotin immunoperoxidase technique (StrAviGen; BioGenex, San Ramon, USA) on freshly cut, $5 \mu \mathrm{m}$ paraffin wax sections that had been flattened onto polylysine coated glass slides at room temperature overnight. Clone 213-4.4 (Oncogene Science, Uniondale, USA), specific for amino residues $34-50$ at the C-terminus of TGF $\alpha$, was used at a concentration of $0.5 \mu \mathrm{g} /$ ml. EGF was detected using a rabbit polyclonal antibody (Z12; Santa Cruz Biotechnology) raised against recombinant human EGF and used at a concentration of $2.5 \mu \mathrm{g} / \mathrm{ml}$. Affinity purified monoclonal antibody directed against TGF $\beta$ (clone TB21; mouse IgG $k$, Serotec, Oxford, UK), raised against purified TGF $\beta 1$ from human platelets, ${ }^{29}$ was used at a concentration of $0.33 \mu \mathrm{g} / \mathrm{ml}$. This antibody has been shown to neutralise the action of TGF $\beta 1$ on the growth of various target cells in vitro (mink lung epithelial cells; NRK 49F cells) and to react with recombinant human TGF $\beta 1$ and purified human platelet TGF $\beta 1$ by ELISA. On western blotting, single bands corresponding to the $12.5 \mathrm{kD}$ monomer and $25 \mathrm{kD}$ dimer were observed from crude acid/ethanol extracts of human platelets after electrophoresis in reducing and non-reducing conditions, respectively. At the present time, possible crossreactivity with other TGF $\beta$ isotypes and latent forms of TGF $\beta$ has not been tested.

In brief, deparaffinised sections were immersed in $0.3 \%$ hydrogen peroxide in buffer for 10 minutes to abolish endogenous peroxidase activity, washed and then overlayed with primary antibodies at room temperature for two hours. After washing, the sections were further treated with biotinylated multi-link (BioGenex, 1 in 75 dilution in buffer containing $10 \%$ normal human serum; one hour at room temperature), washed and then overlaid with peroxidase-labelled streptavidin (BioGenex, 1 in 75 dilution; one hour at room temperature). Bound peroxidase was visualised by immersing washed sections in 3,3'diaminobenzidine (five minutes) and reaction products subsequently enhanced by treatment with $0.5 \%$ copper sulphate $(\mathrm{w} / \mathrm{v}$ in saline; five minutes). Stained sections were lightly counterstained in Meyer's haematoxylin and mounted in Xam. Phosphate buffered saline (PBS; $0.01 \mathrm{M}$; pH 7.6) was used for all reagent dilutions and washes.

Table 1 Immunoreactivity of odontogenic cyst epithelium with antibodies directed against TGFa and EGF

\begin{tabular}{|c|c|c|c|c|c|c|c|c|c|}
\hline \multirow[b]{2}{*}{ Epithelial lining } & \multirow{2}{*}{$\begin{array}{l}\text { Number of } \\
\text { specimens }\end{array}$} & \multicolumn{4}{|c|}{$T G F a$} & \multicolumn{4}{|c|}{$E G F$} \\
\hline & & $++^{*}$ & + & - & Patternt & ++ & + & - & Pattern \\
\hline $\begin{array}{c}\text { Odontogenic } \\
\text { keratocyst }\end{array}$ & 27 & & & & & & & & \\
\hline Solitary & 10 & 9 & 1 & 0 & 10 & 0 & 10 & 0 & 0 \\
\hline Recurrent & 8 & 7 & 1 & 0 & 1 & 1 & 7 & 0 & 1 \\
\hline Syndrome & 9 & 8 & 1 & 0 & 0 & 1 & 8 & 0 & 1 \\
\hline Dentigerous cyst & 10 & 5 & 5 & 0 & 2 & 0 & 8 & 2 & $3 \ddagger$ \\
\hline Radicular cyst & 10 & 5 & 5 & 0 & 1 & 0 & 8 & 2 & $5 \ddagger$ \\
\hline
\end{tabular}

^Number of cases showing degree of reaction: ++, strong; +, weak; -, no staining.

†Number of cases showing predominantly basal and suprabasal staining. All others showed predominantly suprabasal staining only. ¥Two specimens each of dentigerous and radicular cysts were EGF negative. 
A

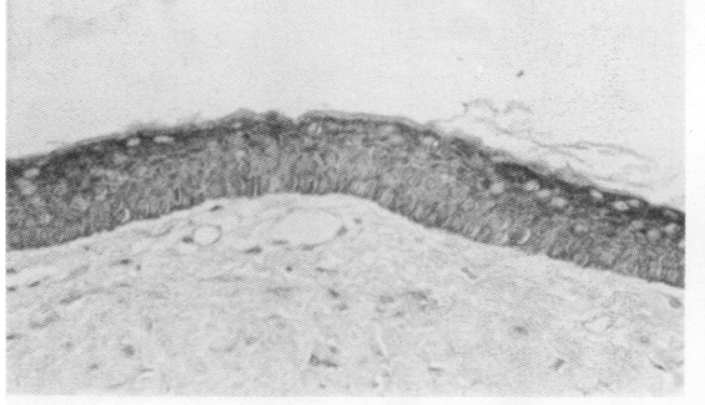

C
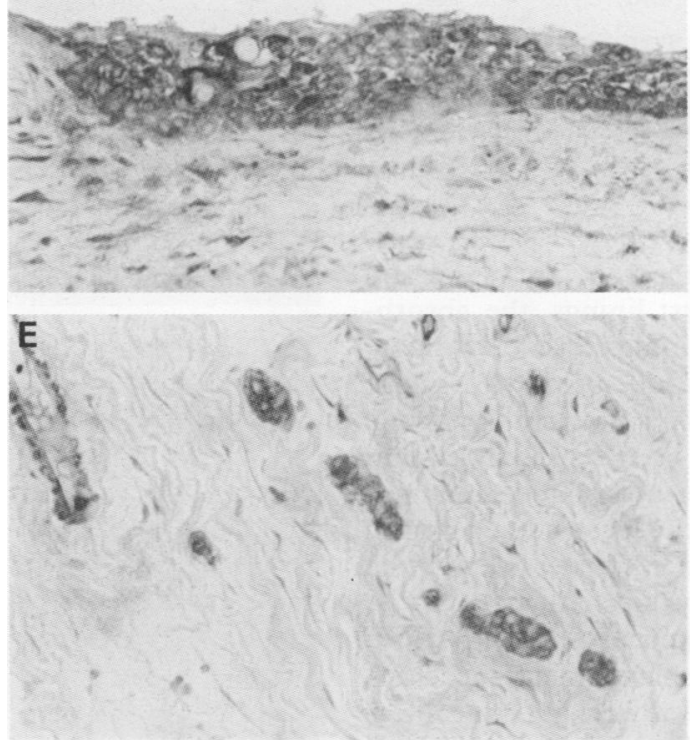

B

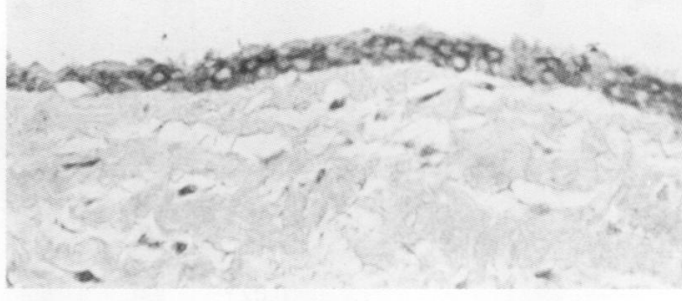

D
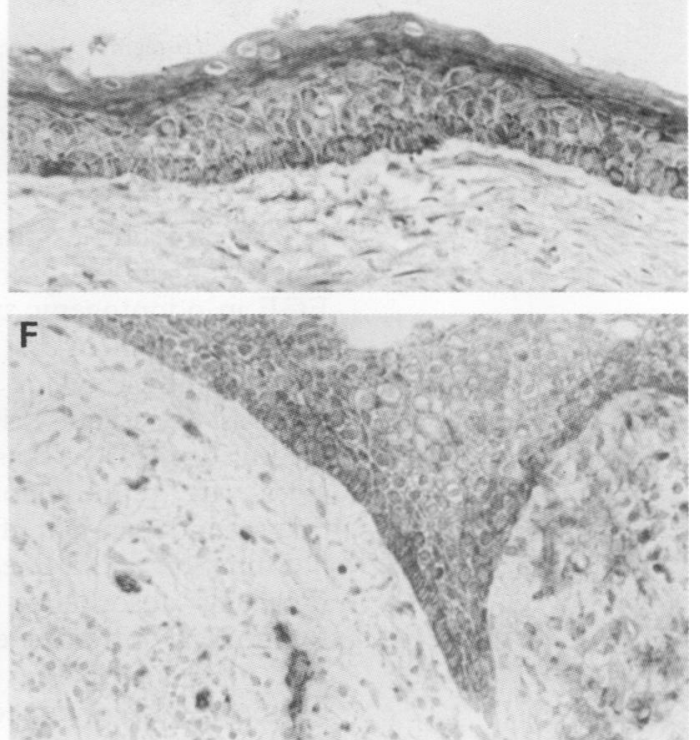

Figure 2 Staining of odontogenic keratocysts ( $A$ and $D)$, dentigerous $(B)$ and radicular cysts $(C)$, and epithelial rests within the connective tissue wall (E) for TGFa. Note the staining pattern of strong basal and granular layer reactivity (D) in some odontogenic keratocyst linings, and strong TGFa reactivity in connective tissue wall associated with the presence of inflammation $(F)$.

Optimum dilutions, times and temperatures were determined in preliminary experiments on a variety of routinely fixed and processed tissue blocks. Positive staining was abolished when normal mouse IgG, a monoclonal antibody of irrelevant specificity (MRC OX52, IgG2a anti-rat T cell; Serotec) or PBS were used as the first layer and when one or both second layers were omitted. The specificity of the reaction was determined by preincubation of antibodies with 10-fold excess by weight of their corresponding peptides at $4^{\circ} \mathrm{C}$ overnight (TGFa, Sigma, Poole, Dorset, UK; EGF, Santa Cruz Biotechnology; TGF $\beta$, Serotec).

EVALUATION OF TISSUE SECTIONS

Overall, TGF $\alpha, E G F$ and TGF $\beta$ staining intensity of different cyst linings was scored subjectively using a semiquantitative scale: strong $(++)$, weak $(+)$ and negative $(-)$. In addition, the distribution of TGF $\alpha$ and EGF staining within the cyst linings was scored to indicate which epithelial layer(s) exhibited the strongest reaction: basal and suprabasal; and suprabasal. Because substantial staining of TGF $\beta$ was also seen in the fibrous tissue capsules of odontogenic cysts, its staining intensity was assessed subjectively for both cyst
A

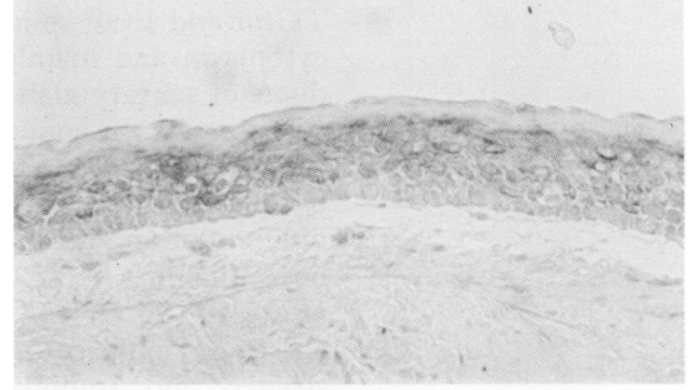

B

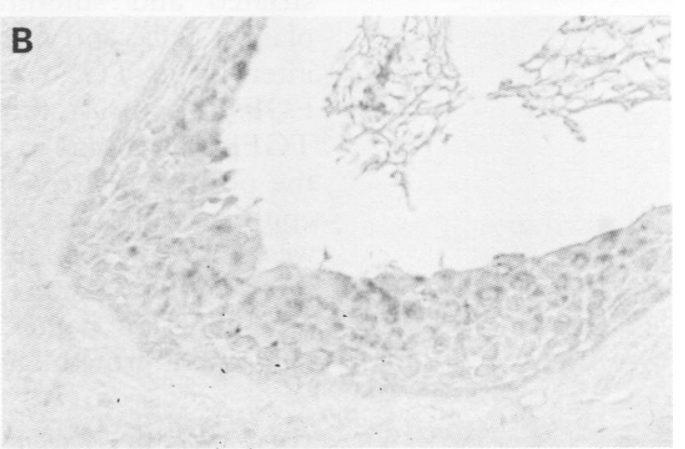

Figure 3 Staining of an odontogenic keratocyst $(A)$ and a dentigerous cyst (B) for EGF. 


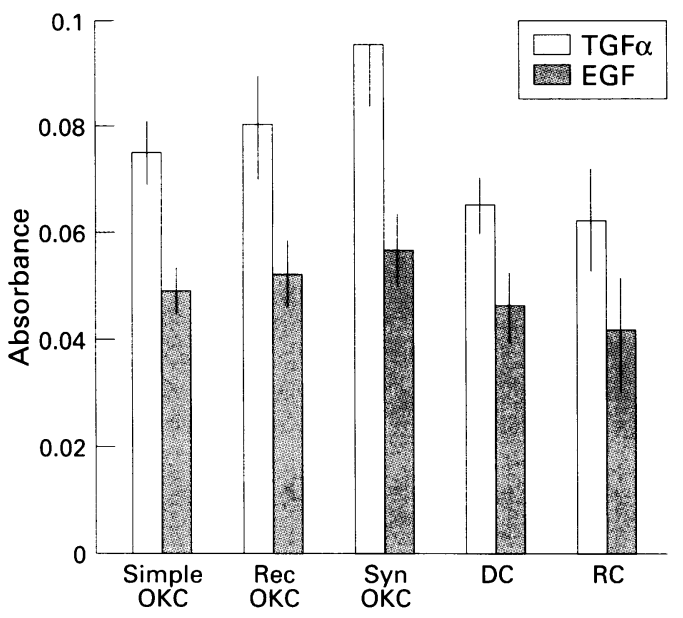

Figure 4 Histogram showing TGFa and EGF absorbance readings of the epithelial linings of odontogenic cysts measured by TV image analysis (mean absorbance (SD)). Rec $=$ recurrent $;$ Syn $=$ syndrome $; O K C=$ odontogenic keratocyst.

linings and fibrous tissue capsules. To assess objectively the immunoreactivity of TGF $\alpha$ and $\mathrm{EGF}$ in odontogenic cyst linings, the absorbance of the stained cyst linings was determined, at a magnification of $\times 200$, using TV image analysis (Seescan Prism; Seescan Imaging, Cambridge, UK). This image analysis system gives true, reproducible absorbance readings that are independent of the level of background illumination and a linear response over a wide range of absorbance values $(0$ to +3$) .{ }^{3031}$ Preliminary titration experiments with EGF and TGF $\alpha$ antibodies showed that the chromogen density obtained at working concentrations was within this linear response range. Measurements were made in five areas of cyst lining in each case. Data were analysed statistically using the Mann-Whitney U-test.

\section{Results}

STAINING PATTERN IN CONTROL TISSUES

TGF $\alpha$ and EGF staining was localised to the cytoplasm and mainly detected in epidermis, ducts of salivary glands and epithelial tumour components. In epidermis and oral squamous cell carcinoma, strong reactivity for TGF $\alpha$ was usually detected in areas showing squamous differentiation and in central areas of tumour nests. Staining in the basal cell layers was weak or absent (fig 1A). TGF $\alpha$ positive staining was also found in the cytoplasm of endothelial cells, striated and smooth muscle, macrophages, plasma cells, and fibroblasts. Overall, staining intensity of TGF $\alpha$ was stronger than that of EGF. By contrast, the most intense staining for TGF $\beta$ was found in the connective tissues of the positive control specimens and within the epithelium, it was extracellular and usually weaker. However, the staining reactions of all three antibodies were completely abolished by preincubation with excess corresponding recombinant growth factor (fig 1).

TGF $\alpha$ AND EGF STAINING IN ODONTOGENIC CYSTS Table 1 summarises overall TGF $\alpha$ and EGF staining intensity and pattern of distribution within the epithelial linings of odontogenic
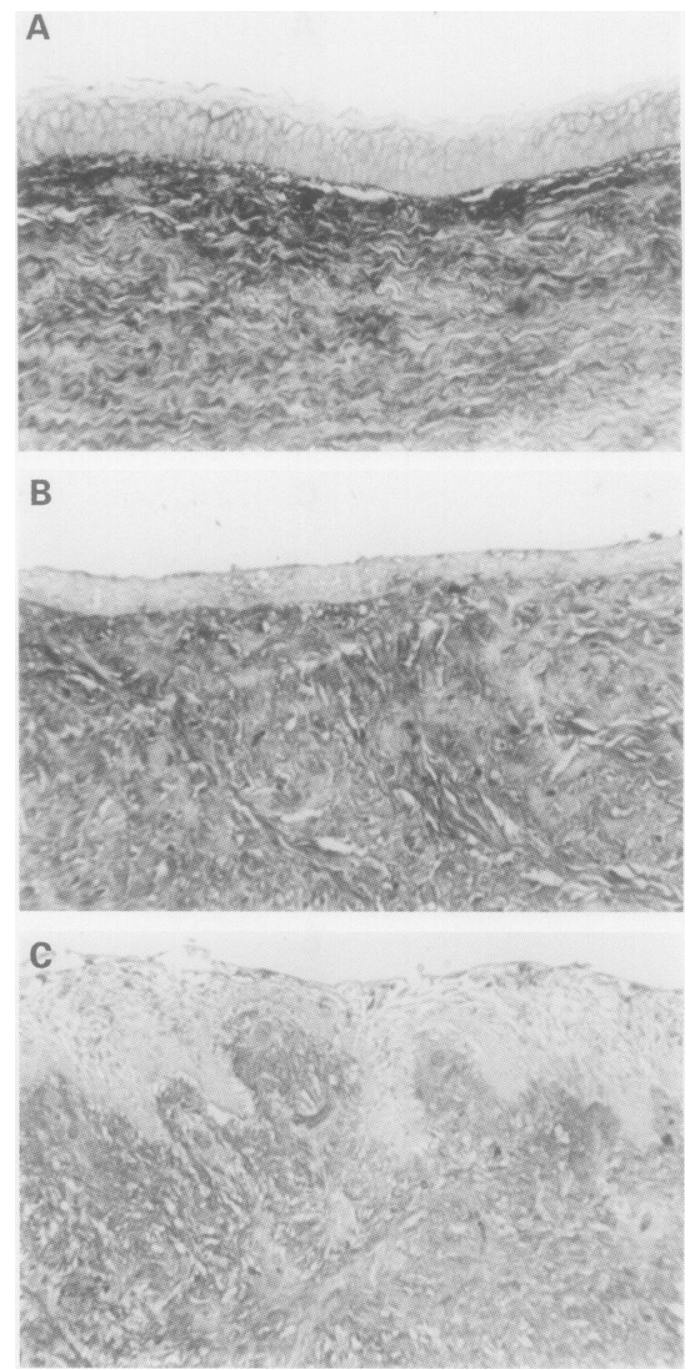

Figure 5 Odontogenic keratocyst $(A)$, dentigerous cyst (B) and radicular cyst (C) stained for $T G F \beta$.

cysts. The epithelial linings of all cysts showed reactivity for TGF $\alpha$ (fig 2) with those of odontogenic keratocysts exhibiting a stronger reactivity than dentigerous and radicular cysts. Generally, the distribution of TGF $\alpha$ staining did not differ between cyst types: most exhibited predominantly basal and suprabasal reactivity. However, in areas of 10 odontogenic keratocyst linings, strong staining was seen in the basal and upper cellular layers, with weaker reactivity between the two (fig $2 \mathrm{D}$ ). There was no detectable difference between the three subgroups of odontogenic keratocyst (that is, solitary, recurrent, and NBCCS-associated cysts) both in terms of epithelial staining intensity and distribution. TGF $\alpha$ and EGF were also detected in endothelial cells, fibroblasts, and inflammatory cells within the cyst capsules. The staining intensity of these cells for TGF $\alpha$ seemed to be higher in areas associated with inflammatory foci. In odontogenic keratocysts, there was no apparent alteration in TGF $\alpha$ reactivity exhibited by disordered cyst lining associated with areas of inflammation (fig $2 \mathrm{~F}$ ). Epithelial rests also stained strongly for $T G F \alpha$ (fig $1 \mathrm{E}$ ). In all specimens, EGF reactivity was weaker than that for $T G F \alpha$, and two specimens each of dentigerous cyst and radicular cyst were negative. The distribution 
of EGF was also different from that of TGF $\alpha$, being predominantly suprabasal (fig 3 ).

Absorbance measurements for TGF $\alpha$ and EGF expression in different cyst linings, determined by TV image analysis, are summarised in fig 4, and confirm the subjective assessments. The mean values for $\mathrm{TGF} \alpha$ were significantly higher than those for EGF $(p<0.004)$ and TGF $\alpha$ absorbance readings for all three subgroups of odontogenic keratocyst were significantly higher than for dentigerous cysts $(p<0.05)$. Radicular cysts showed great variation in $\mathrm{TGF} \alpha$ absorbance and were only significantly different from the NBCCS odontogenic keratocyst group $(p<0.02)$. This may be partly because of the greater structural variability of radicular cyst linings (for example, intercellular spaces and areas of necrosis) which will affect readings. There were no significant differences in EGF absorbance readings between different cyst types. Within the odontogenic keratocyst group, the only significant difference in TGF $\alpha$ absorbance readings was between NBCCS-related lesions and solitary cysts $(p<0.05)$.

EXPRESSION OF TGF $\beta$ IN ODONTOGENIC CYSTS In contrast to TGF $\alpha$ and EGF expression in odontogenic cysts, the most intense staining of TGF $\beta$ was found in the fibrous tissue capsules, irrespective of cyst type, with the majority of cyst linings exhibiting patchy weak reactivity (fig 5). The epithelial staining appeared to be intercellular and predominantly suprabasal. Consistent strong TGF $\beta$ staining was detected in both cellular (fibroblasts, endothelial and inflammatory cells) and intercellular (matrix, intravascular spaces) components of the connective tissue walls in all cyst types. In some sections, a stronger intercellular reactivity was found in the peripheral part of the tissue with reactivity becoming relatively weaker towards the centre.

\section{Discussion}

Our results on control tissues are consistent with published studies using the same antibodies on paraffin wax sections. ${ }^{10}{ }^{32-34}$ Furthermore, the peptide inhibition studies confirm the specificity of the staining reactions obtained with all three growth factor antibodies on both control and odontogenic cyst specimens.

The results show that epithelial linings of all types of odontogenic cyst express TGF $\alpha$, although the intensity of staining varied between cyst types, with odontogenic keratocyst linings exhibiting more intense reactivity than those of dentigerous and radicular cysts. This is consistent with the higher levels of EGF-R expression, ${ }^{23}$ and proliferating cell nuclear antigen (PCNA) and $\mathrm{Ki}-67$ labelling indexes ${ }^{24} 25$ in odontogenic keratocyst epithelium which suggest that these cysts have an intrinsic growth potential not present in the other types of odontogenic cysts. It has been suggested that coexpression of $\mathrm{TGF} \alpha$ and EGF-R in neoplastic cells gives them a growth advantage over normal cells as antibodies directed against $\mathrm{TGF} \alpha$ or EGF-R antisense oligonucleotides have been shown to inhibit the proliferation of several carcinoma cell lines. ${ }^{35-38}$ The strong TGF $\alpha$ reactivity coincident with the high levels of EGF-R expression in odontogenic keratocyst linings suggest that $\mathrm{TGF} \alpha$ may act as an autocrine growth factor to stimulate cell proliferation or differentiation, or both, in this cyst type. That such a relation may exist is also suggested by the significantly higher levels of TGF $\alpha$ detected in NBCCSodontogenic keratocysts compared with solitary odontogenic keratocysts as it is known that syndrome-related cysts exhibit higher mitotic and $\mathrm{Ki}-67$ labelling indexes. ${ }^{25} 39$

Our previous studies have shown that dentigerous cyst linings exhibit a high level of EGF-R expression and that their staining intensity is similar to that of the odontogenic keratocyst. ${ }^{23}$ However, TGF $\alpha$ staining in dentigerous cyst linings was patchy and weak and its absorbance was significantly lower than that of odontogenic keratocysts $(p<0.05)$. This differential expression of TGF $\alpha$ and its receptor EGF-R by dentigerous cyst linings may indicate that paracrine mechanisms of growth factor control are a more important feature in this type of developmental cyst. It is interesting to speculate that this may be directly or indirectly associated with the apparent indolence of the epithelial linings of this cyst type, which have significantly lower PCNA and $\mathrm{Ki}-67$ labelling indexes. ${ }^{24} 25$

In all cyst types, foci of inflammation in the fibrous capsule were associated with areas of strong stromal TGF $\alpha$ reactivity (fibroblasts, inflammatory and endothelial cells) with no apparent difference in the reactivity of the overlying cyst lining. Interestingly, previous studies have shown an inverse relation between the presence of inflammation and the staining intensity of adjacent overlying epithelium for EGF-R. ${ }^{23}$ Such differences may reflect epithelial-mesenchymal interactions and growth factor/receptor modulation. It is believed that such processes play an important role in modulating cell growth and cell interaction during normal odontogenesis as differential expression of EGF-R and TGF $\alpha$ has been shown to relate to the stages of tooth development in both dental epithelium and dental mesenchyme. ${ }^{13} 1440$

EGF immunoreactivity in the epithelial linings of odontogenic cysts was patchy and weaker than that for TGF $\alpha$, with no detectable differences in staining intensity between cyst types. This difference in reactivity was also a feature of the staining results on control tissues. Similar weak or negative EGF reactivity in conjunction with consistent positive TGF $\alpha$ staining has been reported in various normal tissues $^{3241}$ and tumours, ${ }^{42}$ including odontogenic tumours and oral squamous cell carcinoma. ${ }^{13} 32$ Thus, odontogenic cyst linings are similar to other tissues in that TGF $\alpha$ seems to be the key factor in the potential autocrine loop for stimulation of EGF-R. However, it is important to realise that differences in staining intensity obtained with two different antibodies, for the same or different antigens, do not 
necessarily equate with true quantitative differences in amount of antigen within the section.

Many immunocytochemical studies of TGF $\beta 1$ have relied on two rabbit polyclonal antibodies (anti-CC and anti-LC) directed against unconjugated peptides corresponding to the $\mathrm{N}$-terminal 30 amino acids of TGF $\beta 1 .^{43}{ }^{44}$ The antibodies recognise different epitopes: anti-CC shows predominantly extracellular (mesenchymal) and anti-LC predominantly intracellular (epithelial) reactivity. The close correlation of intracellular staining using anti-LC with in situ localisation of TGF $\beta 1$ mRNA suggests that anti-LC recognises TGF $\beta 1$ at sites of synthesis (latent or precursor form of TGF $\beta 1$ ) whereas anti-CC may detect the active form of TGF $\beta 1$ which is bound to extracellular matrix proteins. ${ }^{43}{ }^{44}$ In this study, the pattern of monoclonal antibody TB21 staining resembles that of anti-CC, mainly showing extracellular and mesenchymal reactivity on both control and odontogenic cyst specimens. Although the isotype specificity of TB21 is not known, its ability to neutralise the action of TGF $\beta 1$ on the growth of various target cells in vitro suggests that it reacts with the active form of TGF $\beta 1 .^{29}$ Therefore, our results may indicate the ubiquitous presence of the active form of TGF $\beta$ in the fibrous tissue capsules of all odontogenic cyst types. However, it is not possible to know whether this is because of locally produced or systemically derived peptide or a combination of both. Further studies are required using isotype specific reagents (antibodies and oligonucleotides/ riboprobes) to characterise the TGF $\beta$ detected and assess the role of active local synthesis.

In conclusion, our results show the presence and differential expression of TGF $\alpha$ and EGF in the epithelial linings of odontogenic cysts. Taken together with our previous data on EGF-R expression, ${ }^{23}$ these results suggest that members of the EGF family (via autocrine or paracrine, or both, pathways) are important and play a differential role in the initiation and growth of odontogenic cysts.

We would like to thank the West Midlands Regional Health Authority for financial support and Mrs Christine Wilson for excellent technical assistance. TJL is partly supported by an Overseas Research Study award.

1 Cohen S. Isolation of a mouse submaxillary gland protein accelerating incisor eruption and eye lid opening in the newborn animal. $\mathcal{F}$ Biol Chem 1962;237:1555-62.

2 De Larco JE, Todaro GJ. Growth factors from murine sarcoma virus-transformed cells. Proc Natl Acad Sci USA 1978;75:4001-2.

3 Reynolds FH, Todaro GJ, Fryling C, Stephenson JR Human transforming growth factors induce tyrosine phosphorylation of EGF-receptors. Nature 1981;292:259-62

4 Gusterson B, Cowley G, Simth JA, Ozanne B. Cellular localisation of human epidermal growth factor receptor. Cell Biol Int 1984;8:649-58.

5 Ushiro $\mathrm{H}$, Cohen S. Identification of phosphotyrosine as a product of epidermal growth factor-activated protein kinase in A-431 cell membranes. $₹$ Biol Chem 1980;255: 8363-5.

6 Barrandon Y, Green H. Cell migration is essential for sustained growth of keratinocyte colonies; the roles of transforming growth factor- $\alpha$ and epidermal growth factor. Cell 1987;50:1131-7.

7 Carpenter G. Receptors for epidermal growth factor and other polypeptide mitogens. Ann Rev Biochem 1987;56: 881-914.

8. Rosenthal A, Lindquist PB, Bringham TS, Goeddel DV, Derynck R. Expression in rat fibroblasts of a human trans- forming growth factor alpha cDNA results in transformation. Cell 1986;46:301-9.

9 Coffey RJ, Derynck R, Wilcox JN, Bringham TS, Goustin AS, Moses HI et al. Production and autoinduction of transforming growth factor- $\alpha$ in human keratinocytes. Nature 1987;328:817-20.

10 Yasui W, Ji Z-Q, Kuniyasu H, Ayhan A, Yokozaki H, Ito H, et al. Expression of transforming growth factor alpha in human tissues; immunohistochemical study and Northern blot analysis. Virchows Arch A 1992;421:513-19.

11 Miettinen PJ. Transforming growth factor- $\alpha$ and epidermal growth factor expression in human fetal gastrointestinal tract. Pediatr Res 1993;33:481-4.

12 Derynck R, Goeddel DV, Ullirich A, Gutterman JU, Williams RD, Bringman TS, et al. Synthesis of messenger RNAs for transforming growth $\alpha$ and $\beta$ and the epidermal RNAs for transforming growth $\alpha$ and $\beta$ and the epidermal growth factor recep

13 Heikinheimo K, Voutilainen R, Happonen R-P, Miettinen PJ. EGF receptor and its ligands, EGF and TGFa, in developing and neoplastic human odontogenic tissues. Int $\mathcal{F}$ Dev Biol 1993;37:387-96.

14 Partanen AM, Thesleff I Localization and quantitation of $I^{125}$-epidermal growth factor binding in mouse embryonic tooth and other embryonic tissues at different developmentooth and other embryonic tissues Dev Biol 1987;120:186-97.

15 Partanen AM, Thesleff I Growth factors and tooth development. Int $\mathcal{F}$ Dev Biol 1989;33:165-72.

16 Kronmiller JE, Upholt WB, Kollar EJ. Expression of epidermal growth factor mRNA in the developing mouse mandibular process. Arch Oral Biol 1991;36:405-10.

17 Kronmillar JE, Upholt WB, Kollar EJ. EGF antisense oligodeoxynucleotides block murine odontogenesis in vitro. Dev Biol 1991;147:485-8.

18 Hu C-C, Sakakura Y, Sasano Y, Shum L, Bringas P, Werb Z, et al. Endogenous epidermal growth factor regulates the timing and pattern of embryonic mouse molar tooth morphogenesis. Int $¥$ Dev Biol 1992;36:505-16.

19 Tam JP. Physiological effects of transforming growth factor in the newborn mouse. Science 1985;229:673-5.

20 Rhodes JA, Fitzgibbon DH, Macchiarulo PA, Murphy RA. Epidermal growth factor-induced precocious incisor eruption is associated with decreased tooth size. Dev Biol 1987; 121:247-52.

21 Partanen AM, Ekblom P, Thesleff I. Epidermal growth factor inhibits morphogenesis and cell differentiation in tor inhibits morphogenesis and cell differentiation in 94.

22 Abbott BD, Pratt RM. EGF receptor expression in the developing tooth is altered by exogenous retinoic acid and EGF. Dev Biol 1988;128:300-4.

$23 \mathrm{Li} \mathrm{T-J,} \mathrm{Browne} \mathrm{RM,} \mathrm{Matthews} \mathrm{JB.} \mathrm{Expression} \mathrm{of} \mathrm{epidermal}$ growth factor receptors by odontogenic jaw cysts. Virchows Arch A 1993;432:137-44.

$24 \mathrm{Li}$ T-J, Browne RM, Matthews JB. Quantification of PCNA ${ }^{+}$ cells within odontogenic jaw cyst epithelium. F Oral Pathol Med 1994;23:184-9.

25 Li T-J, Browne RM, Matthews JB. Epithelial cell proliferation in odontogenic keratocysts; A comparative immunocytochemical study of $\mathrm{Ki} 67$ in simple, recurrent and basal cell naevus syndrome (BCNS) associated lesions. 7 Oral Pathol Med 1995;24:221-6.

$26 \mathrm{Li}$ T-J, Browne R M, Matthews JB. Immunocytochemical expression of parathyroid hormone related protein (PTHrP) in odontogenic jaw cysts. Br f Oral Maxillofacial Surg (in press).

27 Vaahtokari A, Vainio S, Thesleff I Associations between transforming growth factor $\beta 1$ RNA expression and epithelial-mesenchymal interactions during tooth morphoepithelial-mesenchymal interactions during

28 Heikinheimo K, Happonen R-P, Miettinen PJ, Ritvos O. Transforming growth factor $\beta 2$ in epithelial differentiation of developing teeth and odontogenic tumours. $\mathcal{f}$ Clin Invest 1993;91:1019-27.

29 Shi W-K, Ye Q-W, Bao L-P. Biological characterisation of a monoclonal antibody TB21 against TGF $\beta 1$. Acta Biol Expt Sinica 1993;26: 141-50.

30 Lawrence GM, Beesley ACH, Matthews JB. The use of continuous monitoring and computer-assisted image analysis for the histochemical quantification of hexokinase activity. Histochem $¥ 1989 ; 21: 557-64$

31 Mason GI, Matthews JB. In situ determination of different dehydrogenase activity profiles in the linings of odontogenic keratocysts and radicular cysts. Histochem $\mathcal{f}$ 1996;28: 187-93.

32 Christensen ME, Therkildsen MH, Poulsen SS, Bretlau P. Immunoreactive transforming growth factor alpha and epidermal growth factor in oral squamous cell carcinomas. $\mathscr{F}$ Pathol 1993;169:323-8.

33 Terada T, Ohta T, Nakanuma Y. Expression of transforming growth factor-alpha and its receptor during human liver development and maturation. Virchows Arch A 1994;424: 669-75.

34 Scott PG, Dodd CM, Tredget EE, Ghahary A, Rahemtulla F. Immunohistochemical localization of the proteoglycans decorin, biglycan and versican and transforming growth factor- $\beta$ in human post-burn hypertrophic and mature scars. Histopathology 1995;26:423-31.

35 Rodeck U, Williams N, Murthy U, Herlyn M. Monoclonal antibody $\mathbf{4 2 5}$ inhibits growth stimulation of carcinoma cells by exogenous EGF and tumour-derived EGF/TGF- $\alpha$. $\mathcal{J}$ Cell Biochem 1990;44:69-79.

36 Sizeland AM, Burgess AW. The proliferation of morphologic responses of a colon carcinoma cell line (LIM 1215)

(1)


require the production of two autocrine factors. Mol Cell Biol 1991;11:4005-14.

37 Derynck $R$. The physiology of transforming growth factor- $\alpha$. Adv Cancer Res 1992;58:27-52.

38 Karnes Jr WE, Walsh JH, Wu SV, Kim RS, Martin MG, Wong $\mathrm{HC}$, et al. Autonomous proliferation of colon cancer cells that coexpress transforming growth factor $\alpha$ and its receptor. Gastroenterology 1992;102:474-85.

39 Woolgar JA, Rippin JW, Browne RM. A comparative histological study of odontogenic keratocysts in basal cell neavus syndrome and control patients. F Oral Pathol 1987; 16:75-80.

40 Cam Y, Neumann MR, Ruch JV. Immunolocalization of transforming growth factor $\beta_{1}$ and epidermal growth factor receptor epitopes in mouse incisors and molars with a demonstration of in vitro production of transforming activity. Arch Oral Biol 1990;35:813-22.
41 Diaz-Ruiz C, Perez-Tomas R, Cullere X, Domingo J. Immunohistochemical localization of transforming growth factor- $\alpha$ and epidermal growth factor-receptor in the mesonephros and metanephros of the chicken. Cell Tissue Res onephros and metanephros of the chicken. Cell Tissue Res 1993;271:3-8.

42 Barton CM, Hall PA, Hughes CM, Gullick WJ, Lemoine NR. Transforming growth factor alpha and epiderma growth factor in human pancreatic cancer. $f$ Pathol 1991;163:111-16.

43 Flanders KC, Thompson NL, Cissel DS, ObberghenSchilling EV, Baker CC, Kas ME, et al. TGFß1; histochemical localisation with antibodies to differen epitopes. F Cell Biol 1989;108:653-9.

44 Thompson NL, Flanders KC, Smith JM, Ellingsworth LR, Roberts AB, Sporn MB. Expression of TGF $\beta 1$ in specific cells and tissues of adult and neonatal mice. 7 Cell Biol 1989;108:661-9. 